\title{
Literatura e escrita feminina na América Latina
}

\author{
Sara Beatriz Guardia* \\ Universidad de San Martín de Porres
}

\begin{abstract}
Resumo: Uma das características mais notáveis da escrita feminina é a forma direta de interpelar os discursos hegemônicos, criticar e reinterpretar a tradicional cultura latino-americana. Vozes que emergem do silêncio para desenhar novos mapas discursivos na reconstrução da memória e da ficção, o que também significa uma linguagem própria, um espaço de liberaçáo, de reconhecimento de si mesmas e de redefiniçấo. Este artigo segue o desenvolvimento desta escrita ao longo de um intenso processo dos momentos fundamentais da literatura escrita por mulheres na América Latina.
\end{abstract}

\footnotetext{
* Escritora, fundadora e diretora do Centro de Estudios La Mujer en la Historia de América Latina. Entre os prêmios recebidos, foi-lhe concedida a Medalha Simón Bolívar, em 2009, e a Medalha Ville de Bagneres de Bigorre pela publicação de "Europa América Latina al alba del tercer milenio". "La flor morada de los Andes" recebeu os prêmios de Mejor Libro entre los Mejores publicados durante los 12 últimos años, Gourmand World Cookbooks Awards 2008 e Opera House, Frankurt, 2008, entre outros. Sara Beatriz Guardia também é professora da Faculdade de Ciências da Comunicaçáo, Turismo e Psicologia da Universidade de San Martín de Porres, Lima, Peru. Além disso, atua como diretora da Comisión del Bicentenario. Mujer e Independencia en América Latina e da Cátedra José Carlos Mariátegui. O texto foi gentilmente traduzido pela profa. Dra. Janaína Soares Alves, do Departamento de Letras e Artes da Universidade Estadual de Santa Cruz - Ilhéus - Bahia-Brasil
}

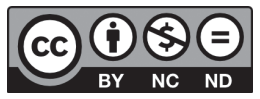

Esta obra está licenciada sob uma Licença Creative Commons. 
Palavras-chave: Rompendo o discurso hegemônico. Processo de literatura escrita por mulheres na América Latina.

Utilizarei neste trabalho o termo literatura escrita por mulheres, embora não questione o termo literatura feminina na sua definição de conjunto de textos literários produzidos por mulheres, muito menos escritura feminina, que abrange o fato de que as mulheres participaram na atividade de escrever, e que a literatura é o modo privilegiado no qual a sua escritura se manifesta (ESTUPIÑÁN, 2004, p. 75). Expressão produzida em sociedades hierárquicas e com estruturas patriarcais, no contexto da dominação espanhola e portuguesa que originou um encontro violento entre dois mundos, e significou o começo de uma relação plena de conflitos, acordos e discrepâncias, em que a exclusão e a marginalidade das mulheres indígenas esteve na base da construção das colônias espanholas; não obstante, os vencidos conservaram até a morte suas crenças em um intenso processo de resistência que repercutiu profundamente em nossa história e em nossa cultura.

O objetivo da história - diz Pierre Vilar - não é "fazer reviver o passado", mas compreendê-lo, o que significa reescrevê-la a partir da revisão de conceitos e métodos existentes para substituí-los por uma nova maneira feminina de abordar o pensamento crítico, com uma orientação que permita conhecer e compreender esse outro lado da história surgido da outra margem (GUARDIA, 2002, p. 202). Tratase de ler os textos escritos pelas mulheres, interpretando seus silêncios, e aquilo que criticam e interrogam da cultura tradicional, como meio de substituir o discurso falocêntrico e apropriar-se de uma identidade que lhes tem sido negada. A escritura converte-se assim, como enfatiza Hélène Cixous, num espaço de liberação, de reconhecimento de si mesmas e de redefinição, mediante as diferentes formas de representação que assume a pluralidade das vozes literárias femininas, ausentes de um cânone quase exclusivamente masculino (GUTIÉRREZ, 2004, p. 33).

Neste processo, farei referência aos momentos constitutivos da literatura escrita por mulheres: a literatura fundacional; que rompe o silêncio no século XIX; a vanguarda literária artística da década de 16 
vinte; o começo de um longo caminho. Escritoras dos anos cinquenta e sessenta; a liberaçáo através da palavra; e o desafio ao futuro sobre a produçáo literária do século XX. Ao longo desta escritura, encontraremos eixos temáticos que aparecem de maneira permanente em romances, contos e poesia, que poderíamos sintetizar em um só anseio, a busca de uma voz própria.

Soror Juana Inés de la Cruz (México, 1648-1695) iniciou no século XVII a escritura feminina na América Latina questionando, através de sua prosa e de sua poesia de incontestável valor literário, as normas da sociedade e da Igreja daquela época. Advogou pelo direito das mulheres à educação e ao desenvolvimento intelectual, a liberdade de expressar sua criatividade e sensibilidade; "como freira declarou sua capacidade de mulher pensante para estudar teologia e conciliar sua religiosidade com uma vida criativa; no entanto, como dramaturga fez algo mais que uma transgressão. Escrever, montar e editar comédias seculares foi um 'crime', ou seja, uma das maiores transgressóes que uma freira enclausurada pode cometer" (SCHMIDHUBER DE LA MORA, 2007, p. 87).

Muitas outras freiras escreveram durante esse período. Tratase de uma escritura autobiográfica controlada por confessores e guias espirituais que regulavam, apoiavam ou desestimulavam os textos. Mediação e consentimento estritamente vinculados às normas e preceitos da Igreja e do Tribunal da Santa Inquisição. Neste diálogo entre a freira e o confessor "que compartilhavam uma vivência inspirada por Deus, a irmã se confessava e escrevia sobre si mesma ou sobre sua ordem e suas irmãs na religião. Ao confessor cabia escutar, decifrar, ordenar os signos de espiritualidade e sua reinterpretação" (LAVRIN; LORETO, 2002, p. 8).

Os únicos textos conhecidos que não pertencem a esta literatura conventual são anônimos. "Discurso en Loor de la Poesía", atribuindo a uma dama que residia em Lima chamada Clarinda, de quem não se tem maiores dados, e que foi publicado em "El Parnaso Antártico" de Diego Mexia de Fernangil, editado em Sevilla em 1608. Depois, em 1621, em "La Filomena", de Lope de Vega, apareceu a "Carta poética Epístola de Amarílis a Abelardo" dirigida no Peru por "Amarilis", 
pseudônimo, ao que tudo indica, pertencente à dona Maria de Rojas y Garay. Nesses textos, o feminino está subordinado ao masculino em uma relação hierárquica, "onde o masculino domina o espaço, o controla, e se projeta como princípio superior frente ao feminino." (QUISPEAGNOLI, 2007, p. 122).

\section{Rompendo o silêncio}

Alcançada a independência da Espanha no século XIX, a constituição das repúblicas significou uma profunda mudança nas instituiçôes de poder sob a influência da transformação socioeconômica que a Europa viveu nos séculos XVII e XVIII. A Revolução Francesa, um novo conceito de democracia, e a Revolução Industrial foram acontecimentos importantes. Tudo isso contribuiu para um estado de preocupação e de revalorização do papel da educação feminina, permitindo que surgisse uma singular presença feminina na literatura, revistas dirigidas e escritas por mulheres, e a formaçấo de clubes literários em que se debatiam os problemas da época.

Mas não foi fácil romper o silêncio para as escritoras latinoamericanas do século XIX, em um clima de intolerância e hegemonia do discurso masculino ainda era bastante denso. Referimo-nos a Gertrudis Gómes de Avellaneda (Cuba 1814-1873), Juana Manuela Gorriti (Argentina 1818-1892), Maria Firmina dos Reis (Brasil 185-1917), Mercedes Cabello de Carbonera (Peru1845-1909), Lindaura Anzoátegui (Bolívia 1846-18980), Clorinda Matto de Turner (Peru 1858-1909), e Adélia Zamudio (Bolívia 1854-1928). Excluídas e marginalizadas do sistema de poder, essas escritoras outorgaram voz aos desvalidos excluídos, questionando as relaçóes inter-raciais e de classe.

Em uma época na qual se acreditava que o escravo não tinha alma nem sentimentos, Gertrudis Gómez de Avellaneda deu voz ao explorado em razáo da etnia e cultura em seu romance $S a b$, publicado em Madrid, em 1841, dez anos antes que aparecesse no "The National Era” o primeiro capítulo de La cabaña del tío Tom, o famoso romance de Harriet Beecher Stowe sobre a escravidão nos Estados Unidos. Em 
Sab, Gómez de Avellaneda descreve a crueldade com que eram tratados os escravos nos engenhos de açúcar de Cuba, em um grau considerado subversivo pelas autoridades coloniais e se transformou em um protesto antiescravagista táo polêmico que só em 1914 foi publicado nesse país. No Brasil, Maria Firmina dos Reis, que como mulata viveu diretamente a segregação social e racial, publicou em 1859, Úrsula, o primeiro romance abolicionista de seu país, e o primeiro escrito por uma mulher. Úrsula aborda a escravidão a partir do ponto de vista do outro, temática também presente em seu conto "A escrava" (1887).

Enquanto que o tema central de Aves sin nido (1889), de Clorinda Matto de Turner, é a denúncia ao maltrato e à opressão que sofriam os índios, além da corrupção e incompetência de juízes, governadores e padres. As personagens femininas constituem as protagonistas do conto. Sáo elas que se erigem em defensoras da justiça transgredindo o discurso patriarcal hegemônico no final do século XIX, no qual as mulheres aparecem indefesas, como pessoas que requerem apoio e necessitam de condução para desenvolver-se na esfera pública. São elas seus aliados, as que condenam os opressores, e a chave da relação entre mulheres e homens, entre índios e brancos (GUARDIA, 2007, p. 171). A reação contra a escritora foi intensa, sendo recriminada por seu anticlericalismo em numerosos artigos, o que resultou em sua exclusão do círculo de intelectuais. Fato que se agravou quando, em 23 de agosto de 1890, foi denunciada pelo arcebispo de Lima porque em "El Peru Ilustrado", revista que ela dirigia, foi publicado um conto do escritor brasileiro Henrique Maximiliano Coelho sobre a vida de Cristo, em que aparece um Jesus mais terreno, interessado em Maria Madalena. $\mathrm{O}$ arcebispo proibiu a leitura da revista, a excomungou e Aves sin nido figurou entre os livros condenados. Pouco depois, viajou em exílio a Buenos Aires onde morreu a 25 de outubro de 1909. Sequer lhe foi permitido regressar ao Peru, e somente quinze anos depois, em 1924, os restos de Clorinda Matto de Tuner foram enterrados em Lima.

Mercedes Cabello foi uma tenaz defensora da educação e da emancipação da mulher, posição que se reflete em vários de seus artigos publicados nos diários da época em Lima. Em 1886 obteve a medalha 
de ouro por seu romance Sacrificio y recompensa, no concurso promovido pelo Ateneo de Lima. A referida obra demonstra sua simpatia pelos patriotas cubanos que combateram na independência da Espanha. No ano seguinte, em 1887, publicou seu romance Eleodora; em 1890, Blanca Sol e Las consecuencias, consideradas como suas obras mais importantes, marcos do romance realista no Peru.

Quando em 1892 publicou El conspirador, a crescente confrontação entre livres pensadores - para quem Mercedes Cabello se constituiu um símbolo - e representantes do poder político e da Igreja, foi agravandose cada vez mais. Com frequência nas páginas dos principais diários foi alcunhada de louca, e isso se repetiu todos os dias durante meses, até que foi sugerido que devesse ser internada em um manicômio logo após o discurso que pronunciara no Liceo Fanning onde defendeu a educação laica, quando, para maior escândalo das pessoas presentes, destacou a necessidade de que as mulheres conhecessem o próprio corpo. Em 27 de janeiro de 1900 foi internada no Manicômio del Cercado de Lima, onde permaneceu nove anos em silêncio e desterro até falecer em 12 de outubro de 1909.

Destaca-se na Bolívia o romance Cuidado con los celos (1893), de Lindaura Anzoátegui, primeira escritora boliviana a denunciar o mau trato e a exploração que sofriam os índios de seu país e a questionar a situação da mulher. Em seu romance, as mulheres e os marginalizados adquirem identidade e se tornam eles mesmos quando se sacrificam (AYLLÓN, 2007, p. 173). Por outro lado, Adela Zamudio em seu romance Intimas, refere-se à impossibilidade do amor e do matrimônio em uma sociedade que marginaliza o sexo e o sujeita à submissão reprodutiva. Em contos e poesia expressou o profundo mal estar que produzia a condição de subordinação das mulheres:

\author{
Cuánto trabajo ella pasa \\ Por corregir la torpeza \\ De su esposo, y en la casa, \\ (Permitidme que me asombre). Tan inepto como fatuo, \\ Sigue él siendo la cabeza, ¡Porque es hombre! \\ (ZAMUDIO, 1999, p. 39)
}


Juana Manuela Gorriti lutou pelos direitos da mulher ainda que com as contradiçóes da sociedade daquela época na idealização da mãe, esposa e virgem. Autora de Panoramas de la vida: coleçáo de romances, fantasia, lendas e descrições americanas, sua produção literária "vai do ponto mais culminante do romantismo até o positivismo do fim do século" (FERREIRA, 2007, p. 163).

Tal como disse Cornejo Polar, em relação ao romance de Clorinda de Matto, a literatura escrita pelas mulheres ao final do século XIX pode ser lida como uma reflexão sobre a modernização e a construção de uma nova identidade baseada na integração da mulher à vida social e econômica, e a integraçáo da comunidade indígena liberada dos abusos aos era submetida.

\section{Vanguarda literária e artística da década de 1920}

A Primeira Guerra Mundial e o triunfo da Revolução Russa influenciaram profundamente as primeiras décadas do século XX. São os anos do surrealismo, da Quimera de Oro de Chaplin e El acorazado Potemkin de Eisestein. Os trabalhadores unem-se em intensas reivindicaçôes pelas jornadas de oito horas e pela organização sindical; surgem novas correntes literárias e artísticas, baila-se o charleston e a valsa. As mulheres cortam os cabelos, despojam-se de seus trajes longos, e proclamam o direito de serem artistas e escritoras. No Peru, José Carlos Mariátegui funda em 1926 a revista Amauta que ele mesmo definiu como de doutrina, arte, literatura e polêmica, através de uma perspectiva crítica e de vanguarda, em que se publicaram artigos, poemas e contos das mais destacadas escritoras daquela época.

As mulheres que escreveram neste período de transição do final do modernismo e desenvolvimento do vanguardismo expressaram um mundo interior pleno de intensidade lírica, posto sem temor nem vergonha de serem mulheres, de se sentirem artistas e livres. Provavelmente por isso, aparecem como pessoas estranhas, revoltadas e muito sensíveis. São as tragédias da história cultural latino-americana: Alfonsina Storni suicidou-se, Delmira Agustini morreu assassinada pelo seu marido, María 
Luisa Bombal tentou assassinar um antigo amante, e María Antonieta Rivas Mercado se suicidou na Catedral de Notre Dame, em Paris.

A figura emblemática dessa época foi a poetisa chilena Gabriela Mistral (1889-1957) e, no Peru, Magda Portal (1900-1988). O tema da maternidade, o desejo de ser mãe e ter filhos é particularmente tratado na poesia de Mistral. Hoje sabemos que "foi mãe, inclusive biológica, ainda que isso não transcendeu publicamente; que perdeu seu filho Yin Yin quando este era adolescente, em circunstâncias trágicas; e que sua visão sobre a maternidade oscila ao calor de suas experiências vitais e de seus trajetos estéticos e ético-políticos que ela vai desenvolvendo" (MORALES; SALOMONE, 2007, p. 487). Já a poeta cubana Dulce María Loynaz (1902-1997) escreveu um poema à contracorrente intitulado: "Canto a la mujer estéril", que foi duramente criticado.

Por outro lado, para Magda Portal, poeta e militante política, a arte é o resultado lógico das diversas tendências sociológicas e filosóficas, e não produto anárquico. Declara que a arte nova corresponde à pósguerra, aos inusitados triunfos da ciência e ao grito de liberdade que lança o homem. "Todo um desfile de cadáveres foi necessário para isto, também milhôes de fantasmas famintos", acrescenta. "A arte se despiu das inúteis pompas de Darío - a beleza em si é estéril, a arte deve ser criadora" (Revista Amauta, n. 5, Lima, janeiro de 1927, p. 12). Nos 7 Ensayos de Interpretación de la Realidad Peruana, Mariátegui (1991, p. 322) enfatiza o advento de Magda Portal. Segundo ele, surge para o Peru a primeira poeta, porque até a sua chegada só havia surgido mulheres de letras.

Alfonsina Storni (Argentina, 1892 - 1938) alcançou popularidade com a publicação, em 1925, de seu poemário Ocre, e teve uma importante presença na vida intelectual do seu país. Em diversos artigos deixou claro "que a mulher náo estava mais disposta a tolerar os ultrapassados limites intelectuais, sociais e políticos e que se encaminhava decididamente ao alcance de sua emancipação" (LONGO, 2007, p. 479). Também tiveram reconhecimento por sua procuçáo Juana de Ibarbourou (Uruguai 18921979) e Delmira Agustini (Uruguai 1886-1914), entre outras.

O gênero autobiográfico, iniciado em 1915 com Boudoir Diary, da brasileira Flora de Oliveira Lima, teve várias seguidoras durante esse 
período como a venezuelana Teresa de la Parra (1889-1936) que em seus romances: Ifigenia, Diario de una señorita que escribió porque se fastidiaba, Memorias de Mamá Blanca, Diario de una caraqueña por el Lejano Oriente, e Diario de Bellevue-Fuenfría-Madrid, mostram aspectos relevantes de sua vida e de sua educação, postulando uma "nova origem da cultura elaborada a partir de uma feminilização da transculturalização latino-americana" (MATTALIA, 2003, p. 145).

Victoria Ocampo (Argentina 1890-1979), escreveu suas memórias em sete volumes. O primeiro, El Archipiélago, está constituído por breves vinhetas de rememoração de sua infância. A chilena María Flora Yánez (1898-1982) publicou Visiones de la infancia (1947), conhecido como um "livro de excepcional relevância já que introduziu a intimidade familiar, o cotidiano dos lares santiaguenses no cenário literário do seu país descritos sob um tom poético" (PACHECO, 2004, p. 124). Diferente é, no entanto, o tom autobiográfico da peruana Zoila Aurora Cáceres Moreno (1877-1958) em seu romance Mi vida con Enrique Gómez Carrillo, publicado em 1929. Nele, a escritora quer estabelecer sua própria verdade, propósito importante se se tem em conta que encobre que seu esposo era homossexual. Neste gênero, o livro mais lido foi Las Memorias de una cubanita que nació con el siglo, de Renée Méndez Capote (1901-1989), que recorda sua infância, a educação das mulheres e as reunióes sociais daquela época.

Entre 1919 e 1950 houve, na Colômbia, uma presença importante de escritoras que até a publicação da antologia de escritoras da Antioquia, publicado no ano 2000, permaneceram no esquecimento. Entretanto, trata-se de 44 contos dos quais 25 foram publicados, sendo que vários deles concorreram ao Concurso Feminino de Literatura de 1921, demonstrando "os obstáculos que as mulheres enfrentavam para competir em pé de igualdade com os escritores pelo seu acesso desigual à educação, e pela falta de apoio ao seu trabalho intelectual" (PÉREZ, 2007, p. 221). Destacam-se as crônicas e contos de costume de Sofía Ospina de Navarro que descrevem, com um agudo sentido de observaçáo e humor, a vida das mulheres da cidade de Medelín. 
Mesmo que a tentativa de assassinato de seu ex-amante, o senador Eulogio Sánchez Errázuriz, dez anos depois de ter terminado a relaçáo amorosa, a escritora chilena María Luisa Bombal (1910-1980) se transformou no alvo de críticas e ataques. Seus romances La última niebla (1935) e La amortajada (1938) representam um marco na literatura latino-americana. Questionam com ironia a sociedade e a classe que coube a ela viver, e exploram profundamente o feminino tradicional. La amortajada tem uma estrutura quase pós-moderna, "pensada desde o momento em que o leitor identifica a voz narrativa principal como um cadáver” (MARTÍNEZ-FERNÁNDEZ, 2007, p. 221).

A rememoração histórica está presente na mexicana Nellie Campobello (1909-1986), autora de Cartucho y Relatos de la lucha en el norte de México, no qual descreve acontecimentos relacionados à revolução mexicana. Da mesma forma, a peruana María Nieves y Bustamante (1865-1947) no seu romance Jorge, el hijo del pueblo (1892) relata os trágicos acontecimentos do levante de Arequipa contra o governo de Castela em 1856, a mais cruel das guerras civis que destroçaram o Peru.

Durante esse período, surgem no México importantes dramaturgas: Catalina D’Erzell, (1891-1950), publicou em 1927: ¡Esos hombres!, obra teatral representativa da condiçấo da mulher mexicana daqueles anos. Amalia de Castillo Ledón (1898-1986), uma das primeiras feministas do México e autora de Cuando las hojas caen, peça que estreou com grande sucesso em 1929. María Luisa Ocampo (1900-1974), em La casa en ruinas (1934), apresentou uma típica família de classe média em que a única missão da esposa era de cuidar do seu marido. Logo, as mudanças produzidas na sociedade mexicana foram refletidas em Cuando Eva se vuelve Adán, de Magdalena Mondragón (1913-1989), e Divorciadas, de Julia Guzmán (1906-1977). Neles, as protagonistas lutam pelos seus direitos, numa época de confrontação com a mulher tradicional, que significava ter muitos filhos, ser submissa e abnegada ao marido (DORIA, 2007, p. 328). Ao passo que, em Divorciadas, aparecem as mulheres que, oprimidas e marginalizadas pelos seus maridos, não têm outra alternativa senão o divórcio, vivido com um grande sentimento de culpa por ter deixado os filhos sem pai. 


\section{O começo de um longo caminho}

A marginalização cultural, política, social e econômica das mulheres, e a pouca autoridade intelectual que lhes era concedida, constituem-se nos temas centrais da obra da poetisa e romancista mexicana Rosario Castellanos (1925-1974). Em um momento em que as mulheres latinoamericanas começavam a percorrer um longo caminho em prol de sua própria voz, para escrever vendo-se como mulheres, Castellanos adverte que "a genialidade aparece como uma espécie de masculinidade superior e em conseqüência disso, a mulher nunca poderá ser genial, pois vive de um modo inconsciente ao passo que o homem é consciente e ainda mais consciente o gênio" (CASTELLANOS, 2005, p. 45).

Os conflitos e problemas que as mulheres devem enfrentar "para se constituir em sujeitos criadores de obras culturais e artísticas" (CANO, 2005, p. 11), analisados e refletidos por Castellanos, deram um importante impulso à literatura escrita por mulheres através de personagens femininos vencidos e em situaçôes limites. Fio condutor que se percebe desde o seu primeiro romance, Balún Canán, publicada em 1957, no qual a defesa dos sem posse, e a resistência dos povos indígenas contra as famílias donas de grandes fazendas, no período de reforma agrária (1935-1940), sob a presidência de Lázaro Cárdenas, aparece na relação entre uma menina e sua babá indígena. São dois mundos separados e enfrentados, os excluídos e os opressores, que a menina vai descobrindo através dos gestos cotidianos e inocentes, que lhe produzem uma dor intensa. No idioma maia, Balún Canán significa os Nove Guardióes em referência às montanhas que protegem Comitán, um antigo povoado indígena situado no conturbado estado de Chiapas.

A menina como protagonista na narrativa latino-americana de meados do século XX não é casual, já que "a novela de formaçâo permite o confronto da protagonista frente aos valores da sociedade em um processo em que põe em jogo os desejos dos indivíduos e suas possiblidades de cumpri-los" (POPE, 2003, p. 237). Como, por exemplo, em Ana Isabel, una niña decente (1949), da venezuelana Antonia Palacio, 
e El peligro (1957), da peruana Sara María Larrabure, embora que nele prime o desejo da liberdade e anseio em perder o medo.

Outra grande figura deste período é a escritora mexicana Elena Garro (1920-1998). Em 1958, publicou suas primeiras peças teatrais em Un hogar sólido. Com seu romance Los recuerdos del porvenir (1963) ganhou o Premio Xavier Villaurrutia. O romance trata sobre a Guerra Cristera onde o tema do poder se apresenta sob uma perspectiva política, mas, sobretudo, fantástica, elemento que permeia em sua obra. Foi a primeira esposa do célebre poeta Octavio Paz e, segundo a pesquisadora mexicana Patricia Rosas Lopátegui, foi menosprezada e esquecida como dramaturga e escritora, sem, inclusive, ter seu trabalho jornalístico desenvolvido durante a década de 1940 - reconhecido . Em que medida este esquecimento tem relaçáo com o grande prestígio de Paz? É uma pergunta que subjaz nas biografias sobre a escritora. Teríamos que dizer também que foi uma opositora tenaz do governo, e que nunca se adequou à sociedade tradicional mexicana, que a negou, porque se atreveu a questionar o poder patriarcal do estado e do marido.

O insólito e a busca de Deus está encarnada na poesia da mexicana Enriqueta Ochoa (1928-2008). Desde o início de sua obra nos anos cinquenta, se esquiva dos olhares estranhos, e como escreve à filha pequena: "Eu me olho e não sou uma cripta em chamas, / uma existência inconforme, sonâmbula,/ carregada de fadiga". Em contrapartida, o oculto, "o que implica o mistério, a cidade labiríntica como metáfora da realidade cotidiana, a busca do espírito, a reflexão sobre o atual", são alguns traços que caracterizam a ficção de Luisa Josefina Hernández (1928) (ESTUPIÑÁN, 2004, p. 9).

O tema da pobreza está presente no romance que Raquel de Queiroz (Brasil, 1910-2003), publicou em 1930, O Quinze, ao passo que a brasileira Patrícia Galvão (1910-1962) irrompe como militante do partido comunista na sua luta contra o governo autoritário de Getúlio Vargas. Publicou Parque Industrial, em 1933 e Paixão Pagu, conto autobiográfico. Patrícia Galvão se atreveu a desafiar um sistema político pelo qual foi presa três vezes, e "provocou uma revolução em um tempo e uma sociedade que não estavam preparados para que uma mulher deixasse 
seu papel de mãe e esposa e se prendesse à busca de uma meta que não fosse o matrimônio" (FERNÁNDEZ-BABINEAUX, 2007, p. 210).

\section{Liberação através da palavra}

Em 1971, com a publicação do livro Valses y otras falsas confesiones, da poeta peruana Blanca Varela (1926 -2009), a voz lírica alcança uma intensidade expressiva "poucas vezes alcançada na poesia do Peru, denuncia abertamente um mundo feito para a guerra entre os países, para o confronto de gênero" (MARTOS, 2002, p. 451), o que origina a degradaçăo dos homens e das mulheres. Em sua obra, Vals del Angelus, diz:

Ve lo que has hecho de mí, la santa más pobre del museo, la de la última sala, junto a las letrinas, la de la herida negra como un ojo bajo el seno izquierdo.

Ve lo que has hecho de mí, la madre que devora a sus crías, la que se traga

sus lágrimas y engorda, la que debe abortar en cada luna, la que sangra todos los días del año. (VARELA, 1974)

É a voz da mulher que está criando seu próprio texto literário, é a moça má da história como María Emilia Cornejo (Peru, 1950-1972) que antes de se suicidar, quando tinha apenas 22 anos, proclamava:

Yo soy la muchacha mala de la historia

la que fornicó con tres hombres

y le sacó cuernos a su marido

soy la mujer que lo engañó cotidianamente

por un miserable plato de lentejas...

soy la mujer que lo castró

con infinitos gestos de ternura

y gemidos falsos en la cama

soy

la muchacha mala de la historia. (CORNEJO, 1994) 
Alejandra Pizarnik (Argentina 1936-1972), a poeta emblemática dos sessenta e setenta, cuja voz, expressão de dor, oscila entre a morte e a atração ao silêncio. Seu suicídio consolidou o mito da poeta maldita, e sua morte "o ato fundador de seu trabalho criativo e, em certo sentido, sua escritura provem de um gesto fatal” (GALVIN, 2007, p. 366). Em Fragmentos para dominar o silêncio, escreve:

Las fuerzas del lenguaje son las damas solitarias, desoladas, que cantan a través de mi voz que escucho a lo lejos. Y lejos, en la negra arena, yace una niña densa de música ancestral. ¿¿Dónde la verdadera muerte? He querido iluminarme a la luz de mi falta de luz. Los ramos se mueren en la memoria. El yacente anida en mí con su máscara de loba. La que no pudo más e imploró llamas y ardimos. (GALVIN, 2007, p. 366)

Como Clarice Lispector (1920-1977) foi escritora de ficção de vanguarda com uso de metáforas íntimas e de ruptura. Em sua obra, revela uma permanente crise de identidade através de um estilo que ela mesma definiu como "não estilo". Os personagens femininos de seus romances e contos são complexos e estấo na luta desde a solidáo e o sentimento de desvantagem, sempre em constante reflexáo sobre si mesmos, falam com eles mesmos e com seu "eu" mais íntimo. O mesmo ato de escrever a conduz ao vazio: "Tenho medo de escrever, é tâo perigoso. Quem tentou, bem sabe. Perigo de remexer o oculto e o mundo não vai à deriva, está oculto nas suas raízes submersas nas profundidades do mar. Para escrever tenho que me colocar no vazio." (LISPECTOR, 1991, p. 19)

São os anos de dor, as mulheres começam a ocupar um espaço na literatura e na vida em permanente confronto com a sociedade patriarcal. Fanny Buitrago (1945), em El hostigante verano de los dioses (1963), questiona a relação entre homens e mulheres; Marvel Moreno (Colômbia, 1939-1995) incorpora em Algo tan feo en la vida de una señora bien (1980) personagens femininos que podem escutar-se e compreender-se como mulheres; Laura Antillano (Venezuela 1950-) 
volta o olhar para sua infância através de uma narrativa fragmentária até chegar a uma narrativa linear. Helena Parente Cunha (Brasil 1930-) em $A$ casa e as casas (1966) incursiona no espaço das mulheres ânsias, refletindo a opressão que sofrem; Lygia Fagundes Telles (Brasil 1923-) ganha com seu livro de contos $O$ cacto vermelho o Prêmio Afonso Arinos, da Academia Brasileira de Letras; Nélida Piñon (Brasil 1937-) publica a partir de 1961 um importante número de romances; Elvira Foeppel (1923-1998), em Círculo do medo (1960) e Muro Frio (1961), apresenta mulheres angustiadas que não conseguem um espaço próprio na sociedade excludente e patriarcal, e entram em conflito porque náo encontram nenhuma saída nem solução.

Rosario Ferré (Puerto Rico 1938-) se constitui em uma figura chave na história cultural da América Latina porque rompe com a tradição feminina ao adotar uma posição política diante da sociedade. Em Papeles de Pandora (1976) e Maldito Amor (1986), as mulheres são rebeldes que pugnam por ocupar um lugar que lhes corresponde em um contexto de luta entre classes sociais, dominação de gênero, da burguesia, e dos Estados Unidos, "através de uma polifonia de vozes femininas que resgatam a linguagem popular e que lutam contra a fragmentação de sua própria identidade e da identidade portorriquenha." (CURIEL, 2007, p. 279)

A repressão política imposta pelas ditaduras na América Latina durante os anos sessenta e setenta, principalmente, se vê refletida na escrita da uruguaia Teresa Porzecanski (1945), através de uma grande metáfora do silêncio sofrido e autoimposto quando era proibido escrever, falar, e inclusive, pensar (VELARDE, 2005, p. 38). A linguagem como espaço de desafio tem uma articulação diferente na peça teatral Fala baixo, da dramaturga brasileira Leilah Assunção (1943-). Nesses anos de rejeição à marginalização e à opressão que as mulheres sofriam, conotação muito próxima ao clima de repressão e a falta de liberdade política imposta pela ditadura, o riso provocado por Fala baixo, "expunha ao ridículo a severa austeridade questionando sem medo os valores do sistema. A própria ditadura percebeu isso e, em 1970, proibiu a peça durante a temporada." (ANDRADE, 2007, p. 345) 
O conto sobre a exclusão da escritora brasileira Carolina Maria de Jesus (1914-1977), Quarto de Despejo. Diário de uma favelada, mostra a violência da fome e a miséria a ponto de o personagem ter a impressão de ser uma favela fora de uso, digno de estar em um quarto de despojos (XAVIER, 2004, p. 60). Nessa mesma linha, e com mais sucesso, surge o livro de Elena Poniatowska (México 1932-) Hasta no verte Jesús mio (1969), sobre a azarada vida de uma humilde mulher chamada Jesusa Palancares, quem conta a própria história. Os personagens de Poniatowska, com a diversidade temática de mais de vinte obras publicadas, são reais, vivem, amam, riem e contradizem, assim, a predileção pelos derrotados, por esse culto mítico ao trágico que explica Octavio Paz, no El laberinto de la soledad, expressáo do imaginário coletivo mexicano em que os derrotados fracassam, mas morrem com dignidade e glória.

$\mathrm{Na}$ década de 1980 a literatura escrita por mulheres já não é o gueto dos anos anteriores, as mulheres figuram nas antologias literárias da América Latina, e se publica uma profusão de livros com trabalhos críticos sobre sua escrita com diversos enfoques em um espaço diferente e alternativo, em que o privado subverte o público. A incorporação de assuntos até então considerados masculinos e o distanciamento de uma temática romântica e testemunhal abrem caminho a novas formas de expressão.

A protagonista de En breve cárcel (1981), de Silvia Molloy, é uma escritora sem nome, fechada em um quarto alugado, que, sem identidade de mulher adulta, tenta formular seu próprio eu (GODSLAND, 2007, p. 307). Enquanto que em Conversación al Sur (1981), de Marta Traba, duas mulheres conversam em uma casa-refúgio. Uma espera notícias de seu filho e da sua nora grávida. A outra, mais jovem, tenta sobreviver às marcas da tortura deixadas em seu corpo e na sua alma. Ambas, cada uma a seu modo, buscam uma voz que lhes pertença em um contexto de violência política.

Silvina Bullrich (1915-1990), Beatriz Guido (1922-1985) e Martha Lynch (1925-1988), transcenderam o âmbito íntimo para se transformar nas agudas e controvertidas críticas da realidade da Argentina em um dos períodos políticos mais violentos e pungentes que 
abrange os anos de 1960 e 1980 . Os problemas sociais constituem o tema central nessas escritoras, com as contradiçôes próprias da época. Por exemplo, Beatriz Guido proclamava o direito das mulheres a serem independentes, mas viveu submetida a sua amante.

La Nave de los Locos (1984), da uruguaia Cristina Peri Rossi, incorpora à escrita feminina o tema da violência e do exílio, baseada em uma metáfora iconográfica do Tapiz de la Creación que está na catedral de Gerona pintado por Bosch, cujo título alude a um escuro método para tratar a loucura. "Estas imagens um tanto quanto inquietantes se entretecem com o fio narrativo da viagem, condição essencial das expulsóes, alienaçóes e buscas existenciais representadas no texto. Por outra parte, é bastante notório que as características recém mencionadas situam de início a esta narrativa original dentro da ficção pós-moderna" (MARTÍNEZ-FERNANDEZ, 2007, p. 429).

A escritora argentina Luisa Valenzuela (1938-), em Libro que no muerde (1980), Cambio de armas (1982), e Donde viven las águilas (1983), pretende resgatar a mensagem original em sua forma oral arcaica (COLLETTE, 2007, p. 257). No conto "La llave" se apropria da curiosidade feminina para transformá-la em um eficaz instrumento para o conhecimento. Seu romance La Travesía (2001) "é um convite a penetrar no labirinto de sua escrita, de empreender um percurso para a psique de uma mulher angustiada pelo peso da memória para chegar ao segredo mais íntimo de sua alma” (MEDEIROS-LICHEM, 2007, p. 531).

Em La premeditación y el azar (1989), de Pilar Dughi (Peru 19562006), chama a atençáo a criação literária a partir da interação entre o privado e o público que é mais evidente em Puñales Escondidos (1998), em que a protagonista deseja ser reconhecida pelo seu trabalho no contexto de uma sociedade patriarcal que a exclui. Também em La Rompiente, de Reina Roffé, (Argentina 1951), o que mais ressalta é a voz que apesar do clima asfixiante tenta se afirmar ser própria. Las Dos caras del deseo de Carmen Ollé (Peru, 1947) tem em comum com o romance de Roffé, "a desesperança e a ausência das metas claras de sua figura central, que igualmente é uma escritora sem muita fé em suas capacidades também 
empreende uma viagem com a companhia somente do desconcerto, seus temores e sua escassez de recursos materiais e emocionais" (REISZ, 2003, p. 343).

Por outro lado, o início do debate sobre temas como nacionalizar teve uma expressão particular na Argentina com o romance de Martha Mercader (1926-2010), Juanamanuela mucha mujer (1982), que abrange um período da história desse país marcado pelas guerras de independência até a institucionalização do estado nacional através da vida de Juana Manuela Gorriti (MARTÍNEZ, 2007, p. 245). Também a insurgência política na América Latina e os movimentos revolucionários constituíram um tema importante na narrativa feminina dessa década. Rigoberta Menchú ganhou em 1983 o Prêmio Casa de las Américas pelo seu livro: Me llamo Rigoberta Menchú, que dá voz a uma mulher excluída por ser mulher, indígena e opositora do regime político. Gioconda Belli (Nicarágua, 1948) vinculou sua escrita ao contexto político-social e teve uma ativa participação na Frente Sandinista de Libertação Nacional. Em seu romance, La mujer Habitada busca criar a si mesma como ser humano através da luta política, e como mulher buscando internamente o sentido de sua vida. Neste processo, deixa entrever a luta interna entra a prática política e a vida cotidiana, e a congruência que isto lhe exige (BELLI, 2007, p. 376).

\section{O desafio do futuro}

Nos anos de 1990 foram produzidas mudanças transcendentais na América Latina, uma nova configuração dos espaços sociais e culturais, a consolidação de organizaçôes feministas e de organizaçóes populares de mulheres, assim como a inclusão crescente da mulher no mercado do trabalho, o que provocou mudanças na família e um novo imaginário coletivo.

A defesa dos sem-posse e excluídos continuou ocupando parte importante da produção literária das mulheres, mas sob a perspectiva da mudança. O romance de Ana Teresa Torres (Venezuela 1944-) Doña Inés contra el olvido (1992) norteia a memória dos negros em prol da 32 
liberdade; a boliviana Alison Spedding, eu seu romance De cuando en cuando Saturnina, relata uma rebeliáo indígena produzida entre os anos de 2070 e 2085 na voz de uma mulher. Carmen Boullosa (México 1954-) faz incursão em romances que poderíamos qualificar de históricos em que se pố ao lado dos humildes e vencidos (PFEIFFER, 2003, p. 259-275), "no universo mágico dos indígenas, abundante em tradições e segredos mítico-religiosos da cultura mexicana/asteca" (CARULLO, 2007, p. 297).

Em La madriguera (1996), de Tununa Mercado (Argentina 1939-), a memória serve para subverter a história através de uma ponte que se estabelece entre a história de uma menina e a história nacional (SEMINET, 2007, p. 294). Ao passo que, no romance de Laura Riesco (Peru 1940-), Ximena de dos caminos (1994), o confronto que uma menina vive entre o mundo do pai, de origem espanhola e funcionário da companhia norteamericana que entâo explorava um entrave mineiro e o das criadas, todas de origem indígena, é o universo que deve transitar entre dificuldades e desafios na exploração de um mundo interior, transformando assim a busca da própria identidade no longo caminho que deverá percorrer para conseguir finalmente sua liberação através da palavra.

Mas o fato mais relevante dos anos noventa foi o boom da literatura escrita por mulheres na América Latina, expressa em quatro romances: La casa de los espiritus (1982), de Isabel Allende (Chile 1942-); Arráncame la vida (1986) de Ángeles Mastretta (México 1949-); Como agua para chocolate (1989) de Laura Esquivel (México 1950-); y Nosotras que nos queremos tanto (1991), de Marcela Serrano (Chile 1951-). Foi dito entâo que o realismo mágico iniciado na América Latina com o romance Cem Anos de Solidão, de Gabriel García Márquez, tinha expressão feminina na Casa de los Espíritos, amplamente reconhecida pela crítica, e que iniciou um discurso que fascinou a década dos noventa: o amor, o ambiente íntimo e a cozinha.

Entretanto, depois houve uma queda com o romance multimidiático de Laura Esquivel, La ley del amor (1995), Mal de amores (1996) de Ángeles Mastretta e as divagaçóes culinárias de Isabel Allende em Afrodita (1997). É provável que o conto linear com influência do 
realismo mágico, a ênfase em temas sentimentais e domésticos, e uma construçáo de personagens típicos onde a protagonista aparecesse como uma supermulher, lhe fora imposto com a ajuda do mercado, um corsé ao romance escrito por mulheres que teve uma curta duraçáo. Mas esta falta de simpatia - afirma Reise - com relaçáo a todo o tipo de conto que náo desafie, desde as bases mesmas da linguagem, os valores hegemônicos e o logocentrismo dominante, pareceria negar a validade e a importância das "tretas del débil”, noção que Josefina Ludmer utilizou convincentemente para analisar a obra de Soror Juana Inés de la Cruz e com a qual a maior parte da crítica feminista esteve de acordo (REISZ, 2003, p. 332).

Mas o certo é que na era da globalização, do fim das utopias e da consolidação dos discursos neoliberais, se percebe, na primeira década do século XXI, uma maior intolerância quanto às diferenças culturais, religiosas e étnicas, nas quais a exclusão e a marginalidade abrangem maiores setores da sociedade. A expressão da subjetividade é cada vez mais negada e tudo parece despersonalizar-se individual e coletivamente. Nessa perspectiva, o desafio está lançado. É necessário dar resposta aos silêncios, examinar os discursos daqueles que disseram muito e nada sobre o matrimônio, a maternidade, o corpo feminino, o espaço íntimo e o espaço público, na construção de uma subjetividade confrontada a novas formas de relação social. E estimular uma consciência de alteridade em defesa de nossa identidade cultural e histórica latino-americana, contra uma civilização negadora da diversidade e da diferença cultural.

[Texto recebido em março de 2013 para esta edição, cuja primeira versão foi apresentada no Seminário Mulher e Literatura, em 2007]

\section{Referências}

ANDREO, Juan; GUARDIA, Sara Beatriz. Historia de las mujeres en América Latina. Murcia: Universidad de Murcia, CEMHAL, 2002. 
ARANGO-KEETH, Fanny. Del Ángel del hogar a la obrera del pensamiento: construcción de la identidad socio-histórica y literaria de la escritora peruana del siglo diecinueve. In:. Historia de las mujeres en América Latina. Murcia. CEMHAL, 2002.

AYLLÓN, Virginia. Cuatro novelistas bolivianas abriendo y cerrando el siglo XX. In: GUARDIA, Sara Beatriz (Edición). Mujeres que escriben en América Latina. Lima: CEMHAL, 2007.

BERG, Mary G. Clorinda Matto de Turner (1852-1909). In:

GUARDIA, Sara Beatriz. Escritoras de Hispanoamérica. Bogotá: Siglo Veintiuno, 1992.

CABELLO DE CARBONERA, Mercedes. Influencia de la mujer en la civilización. El Álbum, Lima, n. 12, 8 ago. 1874.

CARULLO, Sylvia. El culto del agua y su magia en Duerme, de Carmen Boullosa. In: GUARDIA, Sara Beatriz (Edición). Mujeres que escriben en América Latina: Lima: CEMHAL, 2007.

CARRILLO, Francisco. Clorinda Matto de Turner y su indigenismo literario. Lima: Biblioteca Nacional, 1967.

CASTELLANOS, Rosario. Sobre cultura femenina. México: Fondo de Cultura Económica, 2005.

CASTELlanOS, Rosario. Balún Canán. México: FCE, 1995.

CASTRO-KLARÉN, Sara. Narrativa femenina en América Latina. In: Prácticas y Perspectivas Teóricas. Madrid: Iberoamericana, 2003.

CIXOUS, Hélène. La risa de Medusa: ensayos sobre la escritura. Barcelona: Anthropos; San Juan: Editorial de la Universidad de Puerto Rico, 1995.

COLLETTE, Marianella. La Llave de Luisa Valenzuela. In: GUARDIA, Sara Beatriz (Edición). Mujeres que escriben en América Latina. Lima: CEMHAL, 2007. 
CORNEJO POLAR, Antonio. Literatura y sociedad en el Perú: la novela indigenista. Lima: Centro de Estudios Antonio Cornejo Polar Latinoamericana Editores, 2005.

CORNEJO POLAR, Antonio. Escribir en el aire. Ensayo sobre la heterogeneidad socio cultural en las literaturas andinas. Lima: Horizonte, 1994.

CORNEJO POLAR, Antonio. Clorinda Matto de Turner, novelista. Lima: Lluvia Editores, 1992.

CORNEJO, María Emilia. En la mitad del camino recorrido. Lima: Ediciones Flora Tristán, 1994.

DA FONSECA, Dense Pini Rosales. Zoila \& Josephina: uma correspondencia histórica. In.: Constancia Lima Duarte et. al. Gênero e representacão em literaturas de línguas românicas. Coleção Mulher \& Literatura v. V. Belo Horizonte: Universidade Federal de Minas Gerais, 2002.

DOMÍNGUEZ, Nora; PERILLI, Carmen (Comp.). Fábulas del género. Sexo y escrituras en América Latina. Rosario: Beatriz Viterbo, 1998.

DUNBAR TEMPLE, Ella. Curso de la literatura femenina a través del período colonial en el Perú. Revista 3, Lima, 1939.

FERNÁNDEZ-BABINEAUX, María. Patricia Galvão: entre la persona y el personaje. In: GUARDIA, Sara Beatriz. (Edición). Mujeres que escriben en América Latina. Lima: CEMHAL, 2007, p. 210.

FERNÁNDEZ OLMOS, Marguerite; PARAVISINI-GEBERT, Lizabeth. El placer de la palabra. Literatura erótica femenina de América Latina. México: Planeta, 1985.

FERREIRA, Rocío. Transacciones de amor y de dinero: Oro, Género y domesticidad en las leyendas "Andinas" de Juana Manuela Gorriti. In: GUARDIA, Sara Beatriz. (Edición). Mujeres que escriben en América Latina. Lima: CEMHAL, 2007, p. 163. 
FORGUES, Roland. Palabra viva. Narradores. Lima: Ediciones Studium, 1988.

FRANCO, Jean. Las conspiradoras. La representación de la mujer en México. México: Fondo de Cultura Económica, 1993.

GALVIN, Rachel. El 'Gran Silencio' de Alejandra Pizarnik. In: GUARDIA, Sara Beatriz. (Edición). Mujeres que escriben en América Latina. Lima: CEMHAL, 2007.

GARCÍA CALDERÓN, Ventura. Del romanticismo al Modernismo (Prosistas y Poetas Peruanos). París: Sociedad de Ediciones Literarias y Artísticas, 1912.

GARCÍA CHICHESTER, Ana. La mujer en la guerra: hacia una nueva lectura de poetas cubanas del siglo XIX. In: GUARDIA, Sara Beatriz. (Edición). Mujeres que escriben en América Latina. Lima: CEMHAL, 2007.

GARDARSDÓTTIR, Hólmfridur. Literatura argentina: construcción de género e identidad en las obras de Susana Silvestre. In: María Clara Medina (Ed.). Lo público y lo privado: Género en América Latina. Suecia: Red HAINA/ Instituto Iberoamericano, Universidad de Gotenburgo, 2001.

GODSLAND, Séller. El espejo lacaniano y la construcción de la identidade femenina: el caso de En breve cárcel (1981) de Sylvia Molloy. In: GUARDIA, Sara Beatriz. (Edición). Mujeres que escriben en América Latina. Lima: CEMHAL, 2007.

GÓMEZ DE AVELLANEDA, Gertrudis. Sab. Madrid: Biblioteca Virtual Miguel de Cervantes, 2000.

GONZÁLEZ, Patricia; ORTEGA, Elena (Ed.). La sartén por el mango. Encuentro de escritoras latinoamericanas. Santo Domingo: Editorial Huracán, 1984.

GONZÁLEZ VIGIL, Ricardo. La gran novela de Laura Riesco. El Comercio, Lima, 22 enero 1995. 
GUARDIA, Sara Beatriz. (Ed. y comp.). Mujeres que escriben en América Latina. Lima: Centro de Estudios La Mujer en la Historia de América Latina, CEMHAL, 2007.

GUARDIA, Sara Beatriz. En nombre del otro desvalido y excluido por el poder. La escritura de Clorinda Matto y Laura Riesco. In: Mujeres que escriben en América Latina. Lima: CEMHAL, 2007. GUARDIA, Sara Beatriz. José Carlos Mariátegui. Una visión de género. Lima: Imprenta Editorial Minerva, 2006.

GUARDIA, Sara Beatriz. Escritura de la historia de las mujeres en América Latina. El retorno de las diosas. (Comp. y Ed.. Coedición: CEMHAL, Universidad de San Martín de Porres, Universidad Fernando Pessoa (Portugal), Foro de Estudios Culturales de Viena (Austria). Lima: Editorial Minerva, 2005.

GUARDIA, Sara Beatriz. Mujeres Peruanas. El otro lado de la historia. 4. Ed. Lima: Imprenta Minerva, 2002.

GUARDIA, Sara Beatriz. Una conversación con Elena Poniatowska. In: Voces y cantos de las mujeres. Lima: Punto \& Línea, 1999.

GUERRA, Lucía. La mujer fragmentada: historias de un signo. Santiago de Chile: Ediciones Cuarto Propio, 1995.

HOBSBAWM, Eric. El hombre y la mujer: imágenes a la izquierda. In: El mundo del trabajo. Estudios históricos sobre la formación de la clase obrera. Barcelona: Crítica, 1987.

KAMINSKY, Amy. Identidad femenina y paratradición poética: Celebración de mujeres de Amanda Castro., In: Historia de las mujeres en América Latina. Murcia: CEMHAL, 2002.

KAMINSKY, Amy. Reading the Body Politic. Feminist criticism and Latin American Women Writers. Estados Unidos: University of Minnesota Press, 1992. 
LAGOS POPE, María Inés. Relatos de formación de protagonista femenina en Hispanoamérica: Desde Ifigenia (1924) hasta Hagiografía de Narcisa la Bella (1985). In: Narrativa femenina en América Latina. Prácticas y Perspectivas Teóricas. Madrid: Iberoamericana, 2003.

LAVRIN, Asunción; LORETO, Rosalva. Monjas y beatas. La escritura femenina en la espiritualidad barroca novohispana. Siglos XVII y XVIII. México: Universidad de las Américas, Puebla -Archivo General de la Nación, 2002.

LISPECTOR, Clarice. Um Sopro de Vida. 9.ed. São Paulo: Francisco Alves, 1991.

LOCKER, Lucia. Dialéctica en la subversión de los sexos en la autobiografia de Aurora Cáceres. In: GUARDIA, Sara Beatriz. (Edición). Mujeres que escriben en América Latina. Lima: CEMHAL, 2007.

LOHMANN VILLENA, Guillermo. Amarilis Indiana. Identificación y Semblanza. Lima: Fondo Editorial de la Pontificia Universidad Católica del Perú, 1993.

LONGO, Stella M. La prosa periodística de Alfonsina Storni por los derechos civiles de las mujeres. Alfonsina Storni y el campo intelectual. In: GUARDIA, Sara Beatriz. (Edición). Mujeres que escriben en América Latina. Lima: CEMHAL, 2007.

LUDMER, Josefina. Las tretas del débil. In: La sartén por el mango. Encuentro de escritoras latinoamericanas. Puerto Rico: Ediciones Huracán, 1984.

LUONGO MORALES, Gilda; SALOMONE, Alicia. Discurso y maternidad: Entre mandato y (des)obediencia. Poetas latinoamericanas a comienzos del siglo XX. In: GUARDIA, Sara Beatriz. (Edición). Mujeres que escriben en América Latina. Lima: CEMHAL, 2007. MARIÁTEGUI, José Carlos. 7 Ensayos de interpretación de la realidad peruana. Lima: Empresa Editora Amauta, 1991. 
MARIÁTEGUI, José Carlos. Cartas de Italia. Lima: Empresa Editora Amauta, 1991.

MARTOS, Marco. Apuntes sobre la poesía de Blanca Varela. In: Historia de las mujeres en América Latina. Murcia: Universidad de Murcia - CEMHAL, 2002.

MARTÍNEZ, Zulma Nelly. Martha Mercader: escuchando (y oyendo) las voces quedas del pasado. In: GUARDIA, Sara Beatriz. (Edición). Mujeres que escriben en América Latina. Lima: CEMHAL, 2007.

MARTÍNEZ-FERNÁNDEZ, Adriana. Sexo y sensibilidad: Recorridos temáticos y discursivos por la narrativa femenina en La Amortajada, Cambio de Armas,y La Nave de los Locos (1984). In: GUARDIA, Sara Beatriz. (Edición). Mujeres que escriben en América Latina. Lima: CEMHAL, 2007.

MATTALIA, Sonia. Máscaras suele vestir. Pasión y revuelta: escrituras de mujeres en América Latina. Madrid: Iberoamericana, 2003.

MATTALIA, Sonia; ALEZA, Milagros (coords.).Mujeres: escrituras y lenguajes en la cultura hispanoamericana y española. Valencia: Universitat de Valencia, 1995.

MATTO DE TURNER, Clorinda. Índole. Prólogo, Antonio Cornejo Polar. Lima: Instituto Nacional de Cultura, 1974. . Boreales, Miniaturas y Porcelanas. Buenos Aires: Imprenta de Juan A. Alsina, 1902. .Las obreras del pensamiento en la América del Sud. Búcaro Americano, a 1, n.1, 1 feb. 1896, reproducido en Boreales, Miniaturas y Porcelanas.

MASIELLO, Francine. Entre civilización y barbarie. Mujer, Nación y Cultura literaria en la Argentina Moderna. Rosario: Beatriz Viterbo Editora, 1997. 
MEDEIROS-LICHEM, Maria Teresa. El sujeto nómada y la exploración de la memoria en La travesía de Luisa Valenzuela. In: GUARDIA, Sara Beatriz. (Edición). Mujeres que escriben en América Latina. Lima: CEMHAL, 2007.

MOLLOY, Silvia. Acto de presencia. La escritura autobiográfica en Hispanoamérica. México: Colegio de México, FCE, 1996.

. Dos proyectos de vida: cuadernos de infancia de Norah Lange y el archipiélago de Victoria Ocampo. In: Femmes des Ameriques. France: l’Université de Toulouse-Le Miral, 1986.

MUZART LUPINACCI, Zahidé. Escritoras brasileiras do século XIX. Florianópolis: Mulheres, 2009.

PACHECO, Bettina. Memorias de la infancia. In: Gregory Zambrano. (Comp.). Mujer: Escritura, Imaginario y sociedad en América Latina. Mérida: Universidad de los Andes, 2004.

PENAA DORIA, Olga Martha. Las dramaturgas desobedientes de México (19201930). In: Mujeres que escriben en América Latina. Lima: CEMHAL, 2007.

PÉREZ, Paloma. Del “Titán laborador” a las "Muchachas escritoras”. Antología de escritoras antioqueñas, 1919-1950. In: GUARDIA, Sara Beatriz. (Edición). Mujeres que escriben en América Latina. Lima: CEMHAL, 2007.

PINTO VARGAS, Ismael. Sin perdón ni olvido. Lima: Universidad de San Martín de Porres, 2004.

PFEIFFER, Erna. Las novelas históricas de Carmen Boullosa. ¿Una escritura posmoderna?. In: Narrativa femenina en América Latina. Prácticas y Perspectivas Teóricas. Madrid: Iberoamericana, 2003.

PRATT, Mary Louise; MORELLO FROSCH, Marta (Ed.). América Latina: Mujer, escritura, praxis. Nuevo Texto Crítico n. 4, Stanford University. 
QUISPE-AGNOLI, Rocío. ¿Cómo hablar hoy de una identidad femenina colonial? Entre la representación de la realidad y el simulacro discursivo. In: GUARDIA, Sara Beatriz. (Edición). Mujeres que escriben en América Latina. Lima: CEMHAL, 2007

RAMÍREZ VIVAS, Marco Aurelio. La memoria como discurso del poder en Doña Inés contra el olvido.In: Mujer: Escritura, Imaginario y sociedad en América Latina. Mérida: Universidad de los Andes, 2004.

REVISTA AMAUTA (1927). Edición Facsímile. Lima: Empresa Editora Amauta, 1975.

REISZ, Susana. Estéticas complacientes y formas de desobediencia en la producción femenina actual: ¿Es posible el diálogo?. In: Narrativa femenina en América Latina. Prácticas y Perspectivas Teóricas. Madrid: Iberoamericana, 2003.

RIESCO, Laura. Ximena de dos caminos. Lima: Peisa, 1994.

RODRÍGUEZ VILLAMIL, Silvia. Mujeres uruguayas a fines del siglo XIX: ¿Cómo hacer su historia?. Boletín Americanista. Año XXXIII, Universidad de Barcelona, 1992.

SEMINET, Georgia. La estética del espacio y la memoria en La Madriguera de Tununa Mercado. In: GUARDIA, Sara Beatriz. (Edición). Mujeres que escriben en América Latina. Lima: CEMHAL, 2007.

SOARES, Ángelica. La mujer, la casa y la vejez en A casa e as casas, de Helena Parente Cunha. In: Mujer: Escritura, Imaginario y sociedad en América Latina. Mérida: Universidad de los Andes, 2004.

SCHMIDHUBER DE LA MORA, Guillermo. La dramaturgia de Sor Juana Inés de la Cruz, su máxima osadía. In: GUARDIA, Sara Beatriz (Edición). Mujeres que escriben en América Latina. Lima: CEMHAL, 2007.

TAURO, Alberto. Clorinda Matto de Turner y la Novela Indigenista. Lima: Universidad Nacional Mayor de San Marcos, 1976. 
TOVAR CURIEL, Maribel. La rebeldía y la marginalidad de las mujeres en Papeles de Pandora y Maldito Amor, de Rosario Ferré. In: GUARDIA, Sara Beatriz. (Edición). Mujeres que escriben en América Latina. Lima: CEMHAL, 2007.

VARELA. Blanca. Valses y otras falsas confesiones (1964-1971). México: Fondo de Cultura Económica, 1974.

VEGA, Mirna Yazmín Estrella. Gioconda Belli: entre la liberación y la utopía. In: GUARDIA, Sara Beatriz. (Edición). Mujeres que escriben en América Latina. Lima: CEMHAL, 2007.

VELASCO, María Adriana. La crítica feminista, el dedo en la llaga o el cuestionamiento al canon literario. In: GUARDIA, Sara Beatriz. (Edición). Mujeres que escriben en América Latina. Lima: CEMHAL, 2007.

VIEIRA DE ANDRADE, Ana Lucia. La Mujer Dramaturga en el Brasil del Siglo XX: ¿Entre los Márgenes de qué Centro?. In: GUARDIA, Sara Beatriz. (Edición). Mujeres que escriben en América Latina. Lima: CEMHAL, 2007.

VILAR, Pierre. Iniciación al vocabulario del análisis histórico. 2.ed. Barcelona: Editorial Crítica, 1980.

WIETUCHTER, Blanca. Hacia una historia crítica de la literatura de Bolivia (Tomo I, con Alba María Paz Soldán, Rodolfo Ortiz y Omar Rocha). La Paz: Programa de Investigación Estratégica en Bolivia, 2003.

XAVIER, Elodia. Quarto de Despejo. Testimonio de una mujer subalterna. In: Mujer: Escritura, Imaginario y sociedad en América Latina. Mérida: Universidad de los Andes, 2004.

ZAMUDIO, Adela. Intimas. La Paz: Editorial Plural, 1999. 


\section{Women's literature and writing in Latin America}

Abstract: One of the most remarkable features of women's writing is a direct way to question the hegemonic discourses, criticize and reinterpret the traditional Latin American culture. Voices that emerge from the silence to draw new discursive maps for the reconstruction of memory and fiction, which also means a language of its own, a space of liberation, recognition and redefinition. This article follows the development of this writing over an intense process of fundamental moments of the literature written by women in Latin America.

Keywords: Breaking the hegemonic discourse. Process of literature written by women in Latin America.

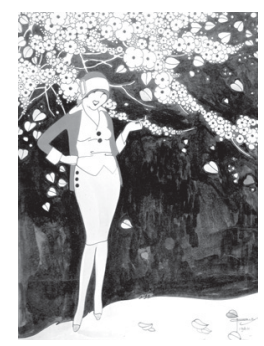

